\title{
Lessons of the month 1: Learning from Harvey; improving blood-taking by pointing the needle in the right direction
}

\author{
Authors: Keith L Dorrington ${ }^{A}$ and Matthew C Frise ${ }^{B}$
}

The taking of blood for diagnostic purposes is a frequent cause of difficulty for physicians. In patients with intact visible or palpable large veins, such as those often seen in the antecubital fossa, a needle or cannula entering from any direction will usually be rewarded with any quantity of blood. In smaller veins in less convenient locations, such as in the hand, the direction of the needle becomes much more important. Failure to take blood is very commonly because of failure to appreciate the direction of flow of venous blood up the arm, and the ubiquitous presence of valves in the veins, both aspects of the circulation clearly described by William Harvey nearly 4 centuries ago. This paper encourages more frequent success with phlebotomy by remembering Harvey's work and pointing the needle in the right direction; this is not always towards the heart.

KEYWORDS: Phlebotomy, vein valves, circulation of the blood

\section{Historical appreciation of venous flow \\ Harvey's discovery of the circulation of the blood}

When William Harvey was asked circa 1657 by Robert Boyle 'What were the things that induc' $d$ him to think of a circulation of the blood?' the answer was that 'Since the blood could not well, because of the interposing valves, be sent by the veins to the limbs; it should be sent through the arteries, and return through the veins, whose valves did not oppose its course that way. ${ }^{1}$ Harvey's diagrams depicting the role of the valves in the veins of the forearm remain the clearest available (Fig 1a), as does his explanation of their role: ${ }^{2}$

This fact may be more clearly shown by tying off an arm of a subject as if for blood-letting ( $A$, A, Figura i). There will appear at intervals (especially in rustics) knots, or swellings, like nodules ( $B$, $C, D, E, F)$, not only where there is branching $(E, F)$, but also where none occurs $(C, D)$. These are caused by the valves, appearing thus on the surface of the hand and arm. If you will clear the blood away from a nodule or valve by pressing a thumb or finger below it

Authors: A associate professor of physiology, University of Oxford, Oxford, UK; ${ }^{B}$ consultant in acute medicine and intensive care, Royal Berkshire NHS Foundation Trust, Reading, UK
( $H$, Figura 2), you will see that nothing can flow back, being entirely prevented by the valve, and that the part of the vein between the swelling and the finger ( $\mathrm{H}, \mathrm{O}$, Figura 2), disappears, while above the swelling or valve it is well distended $(O, G)$.

He went on to emphasise in his Figura 3 that a second finger pushing hard towards the periphery usually fails to cause blood to flow back down the arm, mentioning that these valves appear similar to those 'of the three sigmoid valves placed at the opening of the aorta and pulmonary artery, to prevent, when they are tightly closed, the reflux of blood passing over them'.

\section{Venous infusions and drainage}

It follows from these observations that, if the anatomy follows the pattern depicted in Fig 1a, delivery of substances into the blood via a venous puncture is best served by a cannula facing up the arm in the direction of flow and that drainage of blood via a cannula must permit flow from the periphery. For delivery of laudanum into the hind-limb vein of a dog in 1656, Boyle provided a detailed account of the surgical access achieved by Christopher Wren in Oxford using a 'slender pipe of a syringe' directed 'towards the heart'. 3,4

Conversely, for drainage of blood, if a tube occupies the whole lumen of the vein, it must clearly be pointing towards the periphery from which the blood is flowing. If it is pointing in the opposite direction, blood will need to be able to creep past the cannula before doing an about-turn to flow back out. Early advocates of blood transfusion from animals and humans to patients were clear about the appropriate orientation of drainage and infusion cannulae. Thus, Elsholtz in 1667 (Fig 1b) showed his curved silver phlebotomy drainage cannula facing the hand and the infusion line facing the heart. ${ }^{5}$ A very detailed explanation is given emphasising that 'the curved ends of the tubes, when they are inserted, must be properly directed to pour out and receive blood. 6 Aveling in 1873, in the same manner, showed infusion of blood into a woman suffering post-partum haemorrhage from her carriage driver, the apparently slightly uphill passage of blood being driven by a small manual pump connecting the silver drainage and infusion pipes (Fig 1c).

\section{Strategies to prevent clotting}

The clotting of blood in this pre-anticoagulant era was a constant problem. An attempt to overcome this used speed. By 

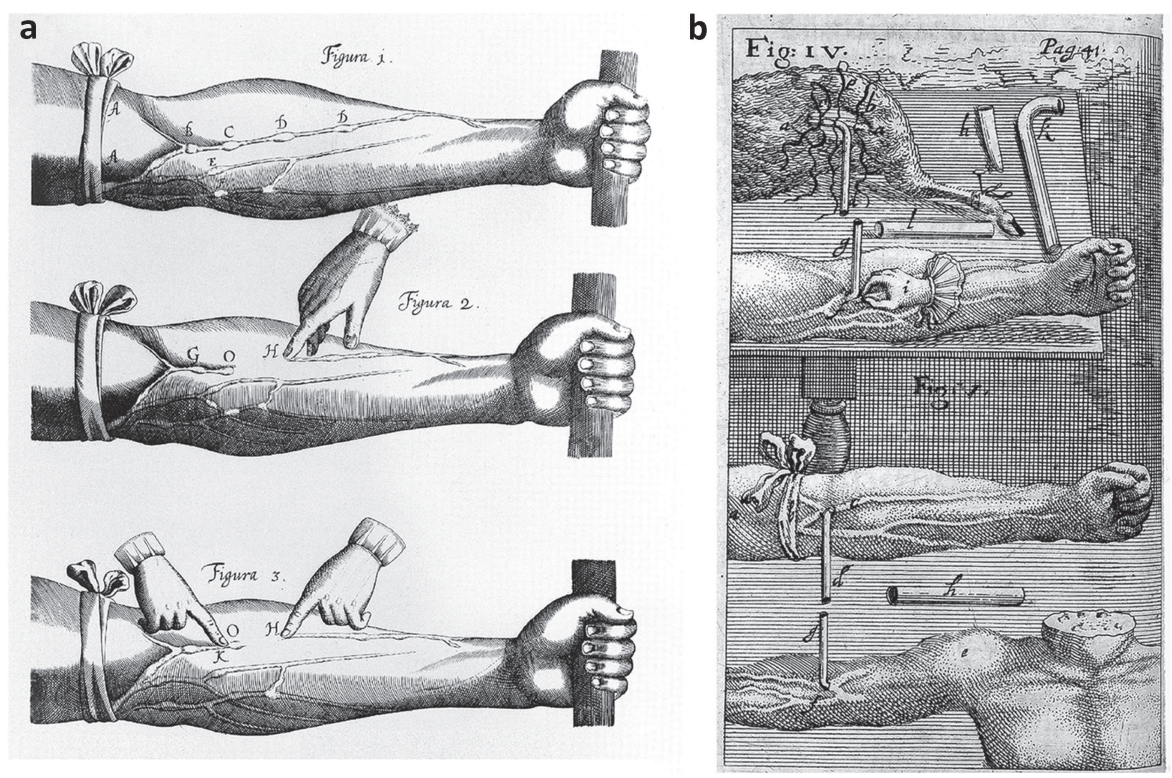

Fig 1. a) Illustration of human forearm veins. Reproduced with permission from Harvey W. Exercitatio anatomica de motu cordis et sanguinis in animalibus. William Fitzer, 1643.

Credit: Wellcome Collection, CC BY. b)

Illustration from Clysmatica Nova by Johann Sigismund Elsholtz in the 1667 edition. Fig IV shows arteriovenous transfusion from lamb to human; Fig $V$ shows veno-venous transfusion between humans. Silver infusion cannula (k) drains human donor blood at (d) placed facing the hand. Reproduced with permission from Elsholtz JS. Clysmatica nova. Berlin: G Schultz for D Reichel, 1667. Credit: Wellcome Collection, CC BY. c) Method of direct transfusion by Aveling in 1873. Post-partum haemorrhage is shown being treated by forearm drainage from a donor silver tube facing the hand, via an 'indiarubber tube to form an
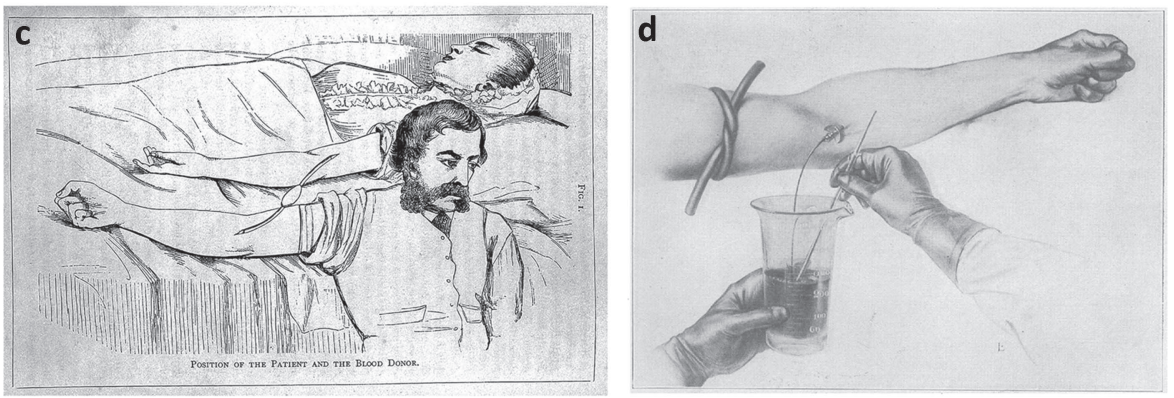
anastomosis between the emittent and recipient veins and a little bulb in the middle to act as an auxiliary heart'. ${ }^{25}$ The operator needed intermittently manually to occlude donor and infusion tubes as the bulb was respectively squeezed and released. Reproduced with permission from Aveling J. Immediate transfusion in England. Obstetrics Journal 1873;1:303. Credit: Wellcome Collection, CC BY. d) Harvesting of blood from the forearm of a donor into a beaker containing citrate to prevent coagulation, as depicted by Lewisohn summarising practice in the period $1914-1924{ }^{12} \mathrm{Here} a$ metal cannula is shown positioned in an antecubital vein pointing towards the hand; blood flow is vigorous. Reproduced with permission from Lewisohn R. The citrate method of blood transfusion after ten years: A retrospect. Boston Med Surg J 1924;190:733-42.

1919, Lindeman reported several hundred transfusions using a cycle of sterilized $20 \mathrm{~mL}$ syringes with a team of operators to take blood from a donor and inject it into the recipient over very short periods of time, each syringe holding blood for only 6-10 seconds. ${ }^{9-11}$ Large (14G) cannulae were inserted over introducers; interestingly, Lindeman nowhere states the direction of insertion of his special cannula in either donor or recipient, but the speed with which large volumes of blood (often over $1 \mathrm{~L}$ ) were transferred suggests unquestioned use of the then traditional orientations. The introduction of citrate anticoagulation permitted a more leisurely approach to harvesting blood, as shown by Lewisohn in Fig 1d, summarising practice over the period $1914-1924 .^{12}$ Drainage was again in the direction of venous flow.

\section{Change in phlebotomy cannulation in the early 20th century}

\section{Blood tests and standardisation}

What is the explanation for the transition to the current total adherence to the practice of phlebotomy conducted with needles pointing centrally? Three factors seem to be relevant. First, the arrival of routine blood tests; second, the technological development of relatively fine needles that could be used to draw modest quantities of blood for laboratory tests from a vein without necessarily occluding the flow from the periphery; and third, the dominance of the use of the median antecubital vein that is usefully supplied by neighbouring superficial veins as well as, in part, by penetrating veins from deep in the arm.

The first widely used screening blood test dates back to Wassermann et al in 1906. This screening for syphilis progressed between the World Wars in the USA, in part because of compulsory pre-marital tests on both husbands- and wives-to-be and accelerated with the arrival of penicillin. ${ }^{13}$ Other tests early in the century included agglutinin reactions prior to transfusion and blood glucose assays on large populations. ${ }^{14}$ An image of a sample being taken for a Wassermann test in Florida in 1941 (Fig 2a) serves to illustrate the now almost universal practice of performing phlebotomy with a syringe and needle pointing headwards in an antecubital vein.

\section{Antecubital and forearm superficial veins}

The median vein of the antecubital fossa is a generous gift of nature to healthcare staff. In many patients it offers a large target generously supplied with blood from more than one 


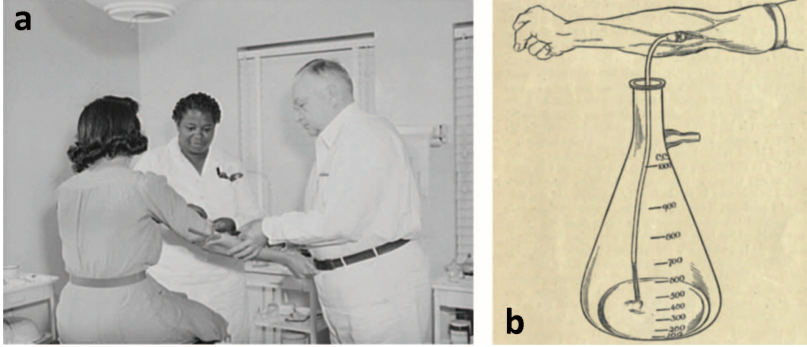

Fig 2. a) Blood being taken for a Wasserman test in a clinic for agricultural workers in Florida 1941. A syringe is being used pointing towards the heart in an antecubital vein. With the introduction of routine blood tests this manner of taking blood became, and remains, the standard approach. Reproduced with permission from Wolcott MP. Taking a Wasserman blood test in clinic for agriculture workers. Okeechobee migratory labor camp, Belle Glade, Florida. Washington: Library of Congress, Prints \& Photographs Division, 1941. b) Depiction of blood donation for the citrate method by G Keynes in 1922. Note the drainage cannula sited in the median basilic vein facing towards the heart. Keynes recommended only using male donors aged $18-25$ years partly on grounds of being best able to draw blood in this manner from these donors. Women were to be excluded from donating. Reproduced from Keynes G. Blood transfusion. London: Hodder \& Stoughton, 1922.

direction, including a penetrating vein from deep in the arm. It is commonly connected to both the basilic vein and cephalic vein. Studies of cadaveric forearm veins by Iimura et al and Kiray et al have elicited much detail regarding the locations of valves and perforating veins. ${ }^{15,16}$ Along the forearm, including in the area of the antecubital fossa, the cephalic and basilic veins were found to be furnished with a valve approximately every $5 \mathrm{~cm}$ and a deep perforating vein approximately every $4 \mathrm{~cm}$ (the basilic vein was more densely occupied by both than the cephalic vein). Iimura et al's classification of valve types is shown in Fig 3, together with the percentages of the different types found by Kiray et al. In the Type 3 valvular arrangement, most valves were found to be within approximately $2-4 \mathrm{~mm}$ of a neighbouring perforating vein. ${ }^{15}$ It seems unfortunate that $90 \%$ of the valves are positioned such a manner that a headwards-pointing phlebotomy needle occluding the vein close to the site of entry would receive no replenishment of flow from a perforating vein from deep in the arm into the cannula, and would apparently empty at most a mere $5 \mathrm{~cm}$, or so, of the superficial vein of blood.

The median basilic vein was the site recommended for blood donation by Keynes in his influential detailed text Blood transfusion published in 1922; this is the segment of the median vein closest to the basilic vein. ${ }^{17}$ Partly on grounds of the suitability of veins, Keynes recommended donors being 'young men between the ages of 18 and 25', adding that 'the use of women as blood donors is to be avoided'. Fig $2 \mathrm{~b}$ shows the recommended route for donation using citrate as an anticoagulant, it being qualified that 'If the vein be of a good size, it makes no difference whether the needle be inserted towards the heart or away from it. ${ }^{17}$ An earlier depiction of blood being taken in the same direction via a suction bottle containing glass beads for the method of defibrination can be found dated to 1913 in the USA. ${ }^{18}$ This route and direction have now become the well-established default for phlebotomy. ${ }^{19}$

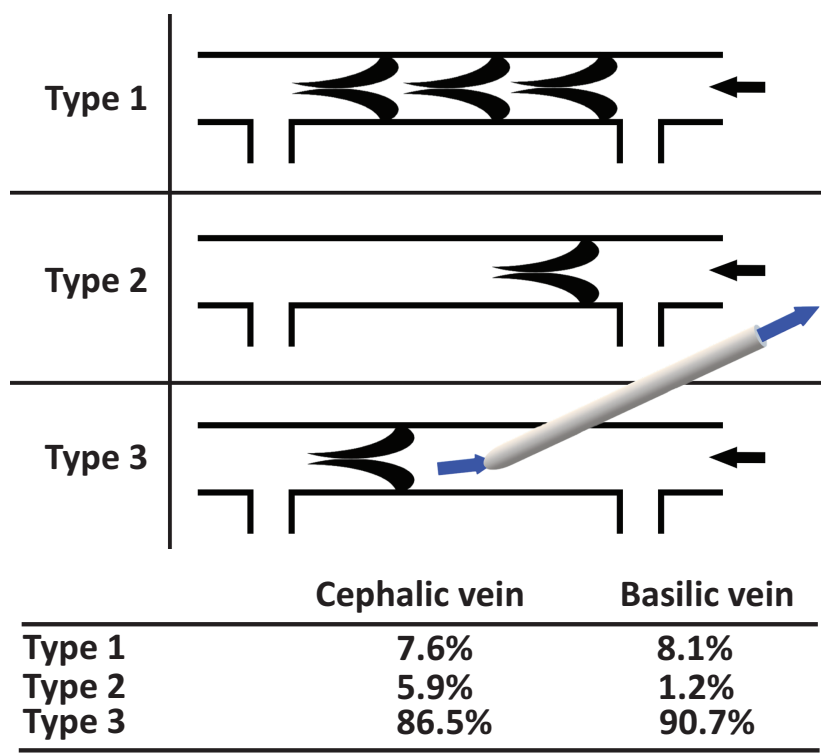

Fig 3. Classification of human superficial forearm vein valve types in relation to the position of perforating veins bringing blood from deep in the arm. Type 1: perforating veins are not present between adjacent valves. Type 2: the valve is closer to the distal perforating vein than the proximal perforating vein. Type 3 : the valve is closer to the proximal perforating vein than the distal perforating vein. A phlebotomy cannula has been drawn entering the Type 3 vein to illustrate the potential for poor flow. Adapted with permission from Iimura A, Nakamura Y, Itoh M. Anatomical study of distribution of valves of the cutaneous veins of adult's limbs. Ann Anat 2003;185:91-5, and data from Kiray et al. ${ }^{16}$

\section{Drawing blood from the direction of flow}

\section{Benefits of a phlebotomy device facing the periphery}

A needle or cannula pointing towards the hand in a patent vein will receive a flow of blood unrestricted by closure of a valve. ${ }^{20}$

Fig 4 a shows drainage in this manner using a 'butterfly' needle in a small vein on the anterior aspect of the wrist; Fig $4 \mathrm{~b}$ shows the use of a cannula to draw blood from a vein on the dorsum of the hand. Insertion of a needle or cannula facing the periphery carries, of course, all the challenges of identifying and entering the vein associated with all phlebotomy, but once in the vein the flow cannot be impeded by the closure of a valve. We recommend this approach to taking blood in patients in whom the antecubital fossa fails to provide a favourable site. A cannula sited in this way can be useful for repeated sampling, for example during exercise testing requiring serial lactate assay. ${ }^{21}$

\section{Potential complications of facing the periphery}

Harvey noted:

I have often noticed in dissecting veins, that no matter how much care I take, it is impossible to pass a probe from the main venous trunks very far into the smaller branches on account of the valvular obstructions. On the contrary it is very easy to push it in the opposite direction, from the branches towards the larger trunks. ${ }^{2}$

Correspondingly, a cannula inserted pointing towards the periphery is at risk of being advanced into the closed cusp of a valve. This will obstruct drainage of blood and has the potential 

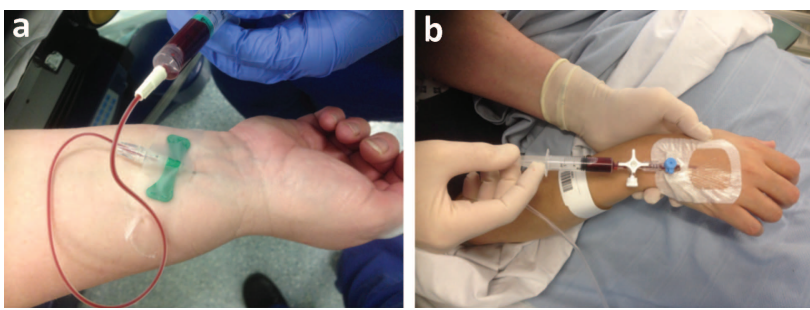

Fig 4. a) Phlebotomy via a 21G 'butterfly' needle (BD Vacutainer ${ }^{\circledR}$ ) from a vein on the anterior aspect of the wrist in a patient in whom other forearm veins were obscured by adipose tissue. Note that the connector for a vacuumed tube has been removed and replaced by a syringe to which gentle suction is being applied; vacuum devices have a tendency to collapse small veins in whichever direction the needle is inserted and manual suction may give better control in such cases. b) Phlebotomy via a 22G (Venflon ${ }^{\mathrm{TM}}$ ) cannula from a vein in the dorsum of the hand in a patient in whom antecubital veins were not accessible. Pointing the cannula towards the periphery ensured a flow of blood unhindered by valves in the vein.

to puncture the vein or damage the valve itself. It can therefore prove useful to identify the location of any nearby valve by using Harvey's method. This method is to empty a segment of vein by stroking along it with a finger, moving away from the heart, and noting the point beyond which a valve prevents the retrograde filling of the vein from the proximal end of the segment, the distal segment still being occluded by the finger. ${ }^{2,20} \mathrm{~A}$ site of insertion can then be chosen well away from the valve. There is the possibility that a cannula placed facing the periphery may be used for drug or fluid administration. Although this appears unlikely to result in harm it may best be avoided by removing the phlebotomy cannula immediately after use or labelling it as for drawing of blood only.

\section{Conclusion}

The restrictions proposed by Keynes on blood donors back in 1922 imply that blood taking can be difficult and the vast majority of clinicians will recognise such difficulties from their own practice. The internet is awash with accounts from patients of difficult and failed phlebotomies, and suggestions from healthcare staff on how to improve technique. A large study of the success rate of outpatient phlebotomy mainly in the USA suggested that fewer than $1 \%$ of phlebotomies failed because of inability to obtain a sample, yet most laboratories took account of the need to have more than one attempt at drawing blood, many up to four times. ${ }^{22}$ Inpatient blood draws by phlebotomists, also mainly in the USA, met with a success rate of $93 \%$, but failure was not always because of technical difficulty. ${ }^{23}$ A recent study of 1,200 hospital patients from India found that only $27 \%$ of phlebotomies were achieved with just one needle prick, most requiring two or three attempts. ${ }^{24}$ Medical staff, particularly anaesthetists and physicians, are familiar with being asked to help with blood taking from patients in whom other staff have failed. While there are clearly multiple different factors contributing to the success or failure of phlebotomy, we believe that there needs to be a focus on the 'elephant in the room' missing from recent studies on, and courses in, phlebotomy: the significance of needle or cannula direction. By highlighting what one of the Royal College of Physicians' best-known alumna demonstrated in the 17 th century, we hope a few more patients and clinicians may be spared the discomfort and frustration of failed phlebotomy.

\section{References}

1 Boyle R. A disquisition about the final causes of natural things wherein it is inquir'd, whether, and (if at all) with what cautions a naturalist should admit them? London: John Taylor, 1688:157-8.

2 Harvey W. Exercitatio anatomica de motu cordis et sanguinis in animalibus: An English translation with annotations (Leake CD, trans). Springfield: Charles C Thomas, 1949.

3 Dorrington KL, Poole W. The first intravenous anaesthetic: how well was it managed and its potential realized? BJA 2013;110:7-12.

4 Hunter M, Davis EB (eds). The works of Robert Boyle. 2003.

5 Gladstone E. Johann Sigismund Elsholtz: Clysmatica Nova (1665): Elsholtz' neglected work on intravenous injection: Part III. Cal West Med 1933;39:119-23.

6 Gladstone E. Johann Sigismund Elsholtz: Clysmatica Nova (1665): Elsholtz' neglected work on intravenous injection: Part IV. Cal West Med 1933;39:190-3.

7 Lefrere J], Danic B. Pictorial representation of transfusion over the years. Transfusion 2009;49:1007-17.

8 Aveling JH. Immediate transfusion in England. Obstetrics Journal 1873;1:303.

9 Lindeman E. Simple syringe transfusion with special cannulas. American Journal of Diseases of Children 1913;13:28-32.

10 Lindeman E. Blood transfusion: Report of one hundred and thirty-five transfusions by the syringe-cannula system. JAMA 1914;62:993-6.

11 Lindeman E. Blood transfusions without a chill by the syringecannula system. JAMA 1919;72:1661-5.

12 Lewisohn R. The citrate method of blood transfusion after ten years: A retrospect. Boston Med Surg J 1924;190:733-42.

13 Morabia A, Zhang FF. History of medical screening: from concepts to action. Postgrad Med J 2004;80:463-9.

14 Wilkerson HL, Krall LP. Diabetes in a New England town; a study of 3,516 persons in Oxford, Mass. JAMA 1947;135:209-16.

15 Iimura A, Nakamura Y, Itoh M. Anatomical study of distribution of valves of the cutaneous veins of adult's limbs. Ann Anat 2003;185:91-5.

16 Kiray A, Ergur I, Tayefi H, Bagriyanik HA, Bacakoglu AK. Anatomical evaluation of the superficial veins of the upper extremity as graft donor source in microvascular reconstructions: a cadaveric study. Acta Orthop Traumatol Turc 2013:47:405-10.

17 Keynes G. Blood transfusion. London: Hodder \& Stoughton, 1922

18 Moss WL. A simple method for the indirect transfusion of blood. Am J Med Sci 1914;147:698-703.

19 Lippi G, Salvagno GL, Montagnana M, Franchini M, Guidi GC. Phlebotomy issues and quality improvement in results of laboratory testing. Clin Lab 2006;52:217-30.

20 Dorrington KL, Aronson JK. Failed phlebotomy? Think William Harvey. BMJ 2014:349:g5232.

21 Formenti F, Beer PA, Croft QP et al. Cardiopulmonary function in two human disorders of the hypoxia-inducible factor (HIF) pathway: von Hippel-Lindau disease and HIF-2alpha gain-of-function mutation. FASEB 2011;25:2001-11.

22 Dale JC, Novis DA. Outpatient phlebotomy success and reasons for specimen rejection. Arch Pathol Lab Med 2002;126:416-9.

23 Howanitz PJ, Schifman RB. Inpatient phlebotomy practices. A College of American Pathologists Q-Probes quality improvement study of 2,351,643 phlebotomy requests. Arch Pathol Lab Med 1994;118:601-5.

24 Gupta A, Dwivedi T, Sadhana, Chaudhary R. Analysis of patient's satisfaction with phlebotomy services in NABH accredited neuropsychiatric hospital: an effective tool for improvement. J Clin Diagn Res 2017:11:EC05-8.

25 Keynes $\mathrm{G}$. The history of blood transfusion, 1628-1914. BJS 1943;31:38-50.

Address for correspondence: Dr Keith L Dorrington, Department of Physiology, Anatomy and Genetics, University of Oxford, Sherrington Building, Parks Road, Oxford OX1 3PT, UK. Email: keith.dorrington@dpag.ox.ac.uk 


\section{Royal College}

\section{Never too busy to learn How the modern team can learn together in the busy workplace}

High-quality learning opportunities are essential for clinicians in training, both for the successful completion of their training and to ensure high standards of care in the NHS.

Published by the Royal College of Physicians in 2018 and supported by Health Education England, Never too busy to learn helps healthcare teams make the most of daily learning opportunities in the workplace.

It explores how 'invitational' learning environments can be created in clinical settings and seeks to answer two key questions:

> How do we create learning opportunities in the clinical workplace?

$>$ How do we maximise the impact of these opportunities?

Never too busy to learn includes case studies that demonstrate tested strategies and explore how to maximise the learning opportunities present within the flow of everyday clinical work.

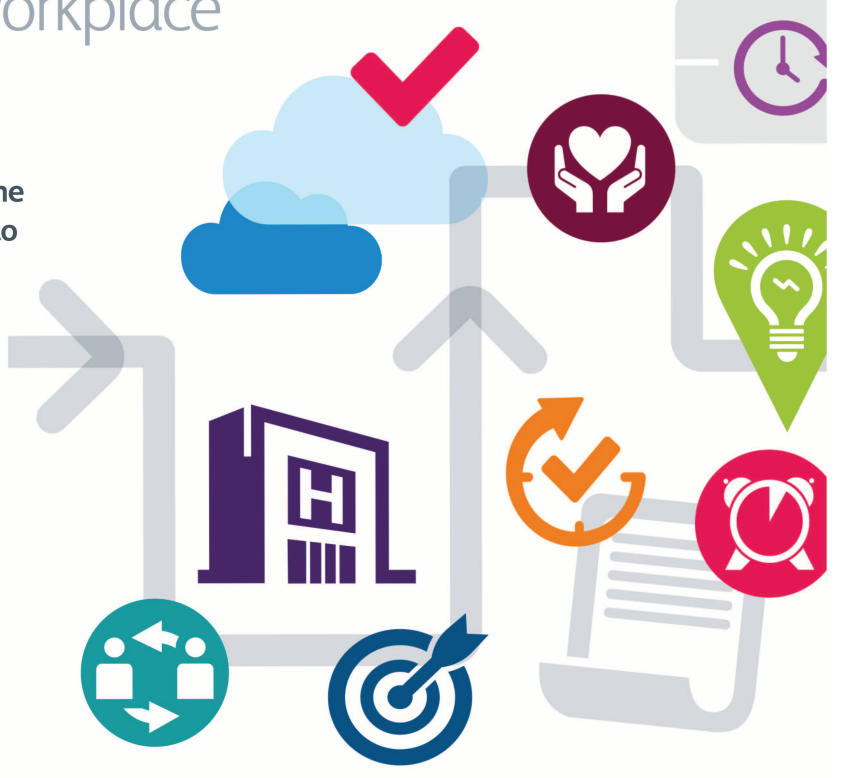

\section{Download the report:} www.rcplondon.ac.uk/never-too-busy-to-learn

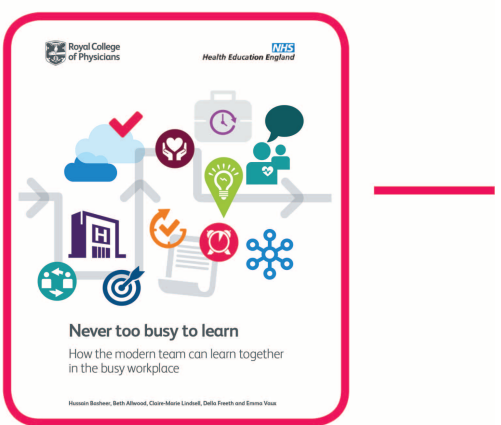

